\title{
Electrochemical Fabrication of Pseudo Platinum Foam and its Application in Methanol Electrooxidation
}

\author{
Hongdan Wang ${ }^{1,2}$, Liqiu Zhang ${ }^{2}$, Hongxia Shen ${ }^{2}$, Lichun Liu ${ }^{1,2^{*}}$, and Lihua Li $^{1^{*}}$ \\ ${ }^{1}$ College of Petroleum Engineering, Liaoning Shihua University, Fu Shun, Liaoning Province, 113000, \\ People's Republic of China \\ ${ }^{2}$ College of Biological, Chemical Sciences and Engineering, Jiaxing University, Jiaxing, Zhejiang \\ Province, 314001, People's Republic of China \\ *E-mail: lichun.liu@mail.zjxu.edu.cn, $\underline{1 \mathrm{lh} 72 @ 163 . c o m}$
}

doi: $10.20964 / 2017.12 .29$

Received: 13 September 2017 / Accepted: 18 October 2017 / Published: 12 November 2017

\begin{abstract}
Porous non-noble metal foams find many industrial applications, however applications of noble metal platinum $(\mathrm{Pt})$ foams were scarce. In this work, we demonstrate a successful fabrication of a pseudo $\mathrm{Pt}$ foam by electrochemically coating $\mathrm{Pt}$ onto a $\mathrm{Ni}$ foam template. A thin $\sim 55 \mathrm{~nm} \mathrm{Pt}$ layer was electrochemically deposited on a $\mathrm{Ni}$ foam with a solution consisting of a low concentration of chloroplatinic acid $\left(\mathrm{H}_{2} \mathrm{PtCl}_{6}\right)$ and polyvinyl pyrrolidone (PVP) additive, using cyclic voltametric deposition technique $(-0.3 \sim 0 \mathrm{~V}$ vs $\mathrm{Ag} / \mathrm{AgCl})$. PVP played a critical role in forming a thin and compact Pt layer. The fabricated pseudo Pt foams were free from cracks and presented good stability in acidic solution. The pseudo $\mathrm{Pt}$ foams contained trace amount of $\mathrm{Pt}$, and exhibited typical chemical properties of metallic $\mathrm{Pt}$ and high surface area same as Ni foam base. With the application of as obtained Pt foam as a catalyst for methanol electrooxidation, the mass-specific current obtained is comparable to the commercial $\mathrm{Pt} / \mathrm{C}$ electrocatalyst. The as-fabricated three-dimensional interconnected porous Pt foams may find versatile electrochemical applications as cost-effective working electrodes or auxiliary electrodes, in fuel cells, (dye sensitized solar cells) DSSCs, sensors, supercapacitors, and so on.
\end{abstract}

Keywords: Pt foam; Ni foam; fuel cell; methanol; electrodeposition; PVP

\section{FULL TEXT}

(C) 2017 The Authors. Published by ESG (www.electrochemsci.org). This article is an open access article distributed under the terms and conditions of the Creative Commons Attribution license (http://creativecommons.org/licenses/by/4.0/). 